University of Nebraska - Lincoln

DigitalCommons@University of Nebraska - Lincoln

\title{
An Exploratory Investigation of Polar Organic Compounds in Waters from a Lead-Zinc Mine and Mill Complex
}

\author{
Colleen E. Rostad \\ cerostad@usgs.gov \\ Christopher J. Schmitt \\ U.S. Geological Survey, cjschmitt@usgs.gov \\ John G. Schumacher \\ US Geological Survey \\ Thomas J. Leiker \\ US Geological Survey
}

Follow this and additional works at: https://digitalcommons.unl.edu/usgsstaffpub

Rostad, Colleen E.; Schmitt, Christopher J.; Schumacher, John G.; and Leiker, Thomas J., "An Exploratory Investigation of Polar Organic Compounds in Waters from a Lead-Zinc Mine and Mill Complex" (2011). USGS Staff -- Published Research. 562.

https://digitalcommons.unl.edu/usgsstaffpub/562

This Article is brought to you for free and open access by the US Geological Survey at DigitalCommons@University of Nebraska - Lincoln. It has been accepted for inclusion in USGS Staff -- Published Research by an authorized administrator of DigitalCommons@University of Nebraska - Lincoln. 


\title{
An Exploratory Investigation of Polar Organic Compounds in Waters from a Lead-Zinc Mine and Mill Complex
}

\author{
Colleen E. Rostad • Christopher J. Schmitt • \\ John G. Schumacher • Thomas J. Leiker
}

Received: 7 May 2010 / Accepted: 5 August 2010 / Published online: 11 September 2010

(C) US Government 2010

\begin{abstract}
Surface water samples were collected in 2006 from a lead mine-mill complex in Missouri to investigate possible organic compounds coming from the milling process. Water samples contained relatively high concentrations of dissolved organic carbon (DOC; greater than $20 \mathrm{mg} / \mathrm{l}$ ) for surface waters but were colorless, implying a lack of naturally occurring aquatic humic or fulvic acids. Samples were extracted by three different types of solid-phase extraction and analyzed by electrospray ionization/mass spectrometry. Because large amounts of xanthate complexation reagents are used in the milling process, techniques were developed to extract and analyze for sodium isopropyl xanthate and sodium ethyl xanthate. Although these xanthate reagents were not found, trace amounts of the degradates, isopropyl xanthyl thiosulfonate and isopropyl xanthyl sulfonate, were found in
\end{abstract}

C. E. Rostad $(\bowtie) \cdot$ T. J. Leiker

US Geological Survey,

Building 95, Box 25046, MS 408, Denver Federal Center,

Denver, CO 80225, USA

e-mail: cerostad@usgs.gov

C. J. Schmitt

US Geological Survey,

4200 New Haven Road,

Columbia, MO 65201, USA

J. G. Schumacher

US Geological Survey, MO Water Science Center, 1400 Independence Road,

Rolla, MO 65401, USA most locations sampled, including the tailings pond downstream. Dioctyl sulfosuccinate, a surfactant and process filtering aid, was found at concentrations estimated at $350 \mu \mathrm{g} / \mathrm{l}$ at one mill outlet, but not downstream. Release of these organic compounds downstream from lead-zinc mine and milling areas has not previously been reported. A majority of the DOC remains unidentified.

Keywords Lead mine · Tailings · Organic compounds $\cdot$ Xanthates $\cdot$ Mass spectrometry

\section{Introduction}

Ores containing lead, zinc, copper, and other metals have been mined from southern Missouri for more than 300 years. The most productive deposits were in the Old Lead Belt in southeastern Missouri and in Kansas and Oklahoma, which were depleted by the 1970s. Mining in these areas left behind contaminated land and water resources due to inefficient extraction technologies available at the time, and early mining predated environmental regulation (Brumbaugh et al. 2005; Schmitt et al. 1993, 2002, 2007a, b).

Discovery of the Viburnum Trend, containing significant lead-zinc reserves, led to the development of the New Lead Belt mining district in southeastern Missouri during the 1960s (Goldhaber et al. 1995). Mines and mills of the New Lead Belt operated under contemporary environmental regulations and utilized 
the most efficient extraction and treatment technologies available (Wixson and Jennett 1975; Wixson 1977). Nevertheless, elevated metal concentrations and effects on biota inhabiting these streams have been reported (Jennett and Callier 1977; Brumbaugh et al. 2005, 2007; Besser et al. 2007, 2009; Allert et al. 2009a, b; Schmitt et al. 1993, 2002, 2007a, b).

By the 1980s, mining activity in the Viburnum Trend declined as ore deposits were depleted, but exploration revealed additional deposits to the southwest. The exploration area is within the Mark Twain National Forest that includes springs, caves, a National Park, and a federally designated Wild and Scenic River. A multiyear interdisciplinary investigation was initiated to evaluate the potential environmental effects of expanded mining in the exploration area (Imes 2002). The study described here, which represents part of the larger investigation, was focused in the New Lead Belt as a model for the potential consequences of expanded mining elsewhere in southern Missouri.

Lead-zinc mining and mineral extraction in the New Lead Belt generate large quantities of solid wastes (Doe Run Company 2003). Mining-related environmental studies have focused on the release of metals and other inorganic materials and the effects of these releases on air quality, surface water and groundwater quality, and biota. However, modern metal beneficiation processes rely heavily on potentially toxic organic compounds such as xanthates, alcohols, and other reagents (Wixson 1977; Okibe and Johnson 2002), which are used in substantial quantities. Xanthates are toxic to aquatic organisms at concentrations $<1 \mathrm{mg} / \mathrm{l}$ and degrade rapidly in aquatic ecosystems (Xu et al. 1988). Although early reports indicated that organic materials released to streams stimulated heterotrophic growth (Wixson 1977), little else is known about the composition or environmental fate of these compounds or their potential effects. The primary objective of our study therefore was to investigate organic chemicals derived from metal mining and beneficiation in effluents and receiving streams at an active mine-mill complex in the New Lead Belt. This area offers an optimum environment for assessing potential environmental effects of mining in southeastern Missouri.

Compounds used in the milling process, their function, and usage are listed in Table 1 (US Environmental Protection Agency 1994). Xanthate reagents are used in the flotation of base and precious metals, which is the standard method for separating valuable minerals, such as gold, copper, lead, or zinc minerals, from host rock containing nonvaluable minerals such as limestone or quartz (gangue). Most of the xanthate reagent is consumed in the process.

Although many of the compounds used in the metal beneficiation process are known (Table 1), the types of organic compounds being discharged from a milling process were unknown. The compounds that can be detected by environmental organic analysis depend on the extraction technique used to isolate analytes and the analytical technique used to analyze the sample extracts. The goal of an extraction technique is to isolate and concentrate the analytes of interest from the sample matrix (Pawliszyn 2003). In this study, a variety of extraction techniques were applied to samples obtained from a typical lead-zinc mine and milling site in 2006. Previous samples from 2005 had been extracted by semipermeable membrane devices (SPMDs) and polar organic chemical integrative samplers (POCIS). The SPMD and POCIS are integrative samplers that are submerged in water at a sample site to uptake organic compounds from water over an extended period. The SPMDs simulate uptake by biota and preferentially uptake hydrophobic or less water-soluble organic compounds (USGS 2004a). The POCIS is designed to uptake more polar organic compounds than the SPMD (USGS 2004b). However, extracts from the SPMD and POCIS integrative samplers analyzed by electrospray ionization/mass spectrometry (ESI/MS) were not significantly different than their corresponding field blanks which accompanied the samplers during deployment, retrieval, and transportation and were processed and analyzed exactly as deployed samplers. Analysis of the SPMD extracts by gas chromatography/mass spectrometry had indicated that samples were devoid of pesticides and acid/base/ neutral extractable semivolatile organic compounds, such as polycyclic aromatic hydrocarbons.

For the 2006 samples, extraction techniques were tailored for very polar organic compounds. The Oasis hydrophilic-lipophilic balance (HLB) solid-phase extraction (SPE) phase isolates a wider range of polar organic compounds than the more traditionally used octadecyl or C-18 phase (Waters Corp. 2003). The sequential XAD-8 and XAD-4 resin column extraction, using a macroporous methylmethacrylate polymer resin, has been widely used for 30 years for the isolation of dissolved organic carbon (DOC) containing very polar 
Table 1 Flotation reagents, their function, and usage from the Fletcher Mill

\begin{tabular}{llr}
\hline Chemical & Function & Tons per year \\
\hline Zinc sulfate & Depressant for sphalerite & 960 \\
Sodium isopropyl xanthate & Primary collector for galena and sphalerite & 857 \\
Isopropyl ethyl thionocarbamate & Collector for sphalerite and chalcopyrite & 6 \\
Mixed alcohol & Frothing agent & 30 \\
Sodium cyanide & Mineral depressant & 1 \\
Ammoniated cupric chloride & Activator for sphalerite & 126 \\
Sulfur dioxide & pH regulation for copper flotation & 360 \\
Starch & Lead depressant & 54 \\
Caustic soda & Mixed with starch & 18 \\
Sodium dichromate & Lead depressant in copper flotation and zinc circuit & 34 \\
Sodium dioctyl sulfosuccinate & Filter aid to improve concentrate dewatering & 8 \\
\hline
\end{tabular}

organic compounds (Leenheer 1981). The Oasis weak anion exchange (WAX) SPE, which is a relatively new phase for extraction of specific anions, was selected specifically to isolate xanthate reagents (Waters Corp. 2003) due to their toxicity and heavy usage in the milling process.

Sample extracts were then analyzed by full-scan positive and negative ESI/MS, which is designed to analyze water-soluble, polar organic compounds (Cole 1997). Negative mode preferentially and specifically ionizes polar acidic organic compounds, whereas positive mode is less selective and more comprehensive and ionizes polar basic organic compounds in addition to almost any polar organic compound that can be protonated. Nonpolar organic compounds, such as alkanes and polycyclic aromatic hydrocarbons, are not ionized (transparent) in either mode.

\section{Methods}

\subsection{Chemicals and Reagents}

All solvents used were Burdick \& Jackson UV grade (VWR Scientific, Philadelphia, PA). Sodium dioctyl sulfosuccinate was purchased from Sigma-Aldrich (St. Louis, MO). Starch (soluble powder) was from Mallinckrodt (St. Louis, MO). Fresh samples of technical processing grade of sodium isopropyl xanthate and sodium ethyl xanthate were graciously provided by a local metallurgical mineral processing company.

\subsection{Study Area}

The site selected for investigation was associated with a New Lead Belt mine-mill complex (Fig. 1). The Fletcher complex, which is located in Reynolds County, includes mines, a mill, and an impoundment that receives water pumped from the mine, and a zero-discharge tailings disposal area and pond (Fig. 1). The mill includes circuits that recover lead, zinc, and copper.

\subsection{Sample Description}

In October of 2006, triplicate 1-1 water samples were obtained from the Fletcher Mill at two separate outlet pipes (Fletcher Mill Out 1, pH 5.25, and Fletcher Mill Out 2, $\mathrm{pH} 8.0$ ), indicative of the initial mining-waste stream, and from the Fletcher Tailings Pond (designated Fletcher Pond, $\mathrm{pH}$ 7.6) to represent possible input into the groundwater system after mixing and dilution. Water samples were filtered through glass fiber filters in the field into Teflon bottles prior to shipment on ice to the laboratory.

\subsection{Extraction of Samples}

Triplicate water samples obtained in October 2006 were extracted using three types of SPE tailored for isolation of very polar organic compounds. The first liter was extracted at ambient $\mathrm{pH}$ using an Oasis hydrophilic-lipophilic balance (HLB) high-capacity 6-ml, 200-mg SPE cartridge (Waters Corp., Milford, 
Fig. 1 Map of Missouri with study areas shown, 80 miles southwest of St. Louis

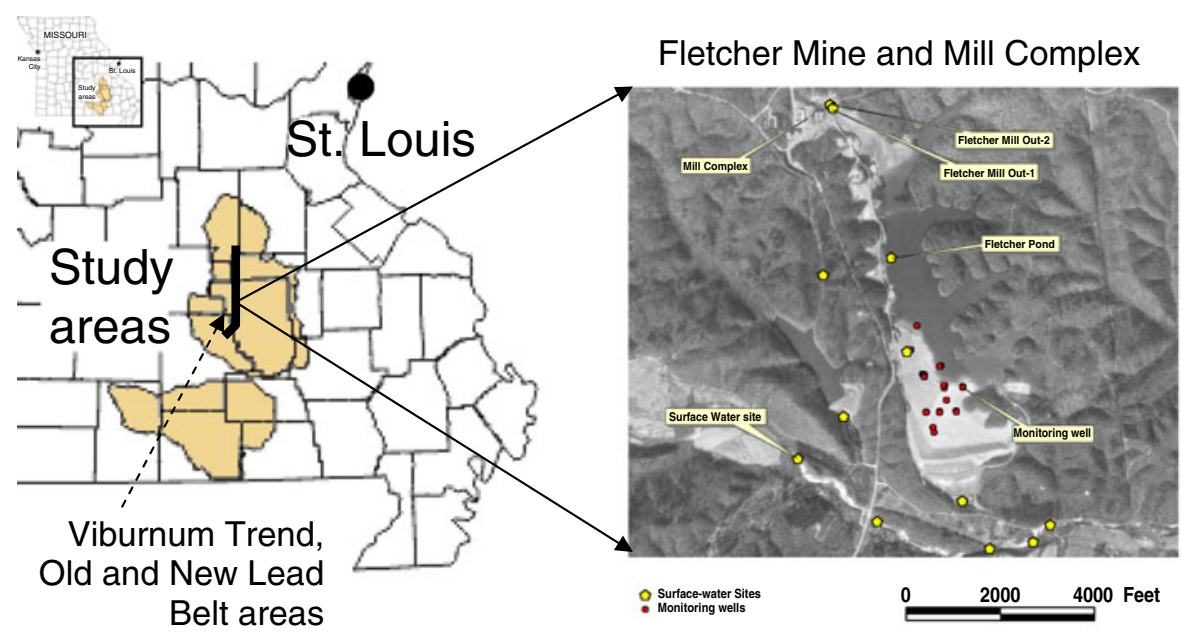

MA) using a Zymark Autotrace automated SPE workstation (Zymark Corp., Hopkinton, MA) and eluted with methanol. The second liter was fractionated on Amberlite XAD resin into two fractions based on increasing polarity: a hydrophobic fraction and a transphilic fraction. The sample was acidified and passed through XAD-8 resin to isolate the hydrophobic fraction and then passed directly through XAD-4 to isolate the transphilic fraction (Leenheer et al. 2000). After rinsing with dilute formic acid, the XAD columns were eluted with 3:1 acetonitrile/water. The third liter was extracted at ambient $\mathrm{pH}$ by SPE on an Oasis WAX high-capacity 6-ml, 30- $\mu \mathrm{m}, 150-\mathrm{mg}$ cartridge (Waters Corp.) using the automated SPE workstation, rinsed with $25 \mathrm{mM}$ acetate buffer and methanol and dried for $10 \mathrm{~min}$. The cartridges were eluted with 20:80 methanol/ acetonitrile with $2 \%(v: v)$ ammonium hydroxide, and the eluates were concentrated and solvent-exchanged to a final volume of $100 \mu \mathrm{l}$ of 90:10 water/methanol prior to electrospray analysis. Recovery of mining reagents (sodium isopropyl xanthate and sodium ethyl xanthate) spiked into tap water at $13 \mathrm{mg} / \mathrm{l}$ had been verified with this WAX method. Extracts were concentrated under a stream of dry nitrogen, transferred to autosampler vials, and refrigerated before analysis.

\subsection{Sample Analysis}

Samples were analyzed using both positive and negative electrospray ionization on an Agilent Series 1100 single quadrupole mass spectrometer
(Agilent Technologies, Wilmington, DE) with unit resolution. Using direct injection analysis, $2 \mu \mathrm{l}$ of the sample were injected into an isocratic stream of 25:75 water/methanol at $0.2 \mathrm{ml} / \mathrm{min}$, transferring the sample directly into the ion source. In this initial investigation, direct injection (without liquid chromatographic column) rapidly pinpointed ions of interest without loss of reactive compounds. No buffer was used in the mobile phase to eliminate its effect on ionization and to minimize adducts (Rostad and Leenheer 2005). Analytical conditions for formation of molecular ions, while minimizing dimers or multiply charged species without fragmentation or adduct ion formation, had been optimized previously by using a variety of polyacid standards (Leenheer et al. 2001, 2002; Rostad and Leenheer 2004). Nitrogen drying gas was introduced at $350^{\circ} \mathrm{C}$ at $12 \mathrm{l} / \mathrm{min}$ with $35 \mathrm{psi}$ nebulizer pressure, at a capillary voltage of $4,000 \mathrm{~V}$. The source fragmentor (capillary exit) was set at $50 \mathrm{~V}$ to minimize fragmentation while ensuring effective ion transmission, and the quadrupole mass spectrometer was scanned from 100 to 1,000 mass-to-charge ratio $(\mathrm{m} / \mathrm{z})$ per second. Although the quadrupole instrument can scan down to $m / z 50$, this was precluded by the possibility of interference from solvent ions. Samples were injected every minute, with triplicate analyses for every sample. Tandem mass spectrometry was performed on an Applied Biosystems 2000 QTRAP tandem mass spectrometer with negative electrospray ionization (Life Technologies Corp, Darmstadt, Germany) using a wide range of fragmentation conditions. 


\section{Results}

Samples of the technical processing grade of milling reagents, sodium isopropyl xanthate and sodium ethyl xanthate, were analyzed to verify proper ionization and determine if unknown inert materials were present. Negative-ion spectra of the mining reagents of sodium isopropyl xanthate, in current use at the mill (Fig. 2a), and sodium ethyl xanthate (Fig. 2b) show that only the active ingredients ionized at $\mathrm{m} / \mathrm{z}$ 135 and 121, respectively, and no inert components were observed.

Water samples contained relatively high concentrations of DOC but were colorless, implying an absence of naturally occurring aquatic humic or fulvic acids (Suffet and MacCarthy 1989). Of the compounds listed in Table 1, those that could contribute to high DOC include sodium isopropyl xanthate, isopropyl ethyl thionocarbamate, mixed alcohol, starch, and sodium dioctyl sulfosuccinate. However, isopropyl ethyl thionocarbamate (molecular weight 147 , expected negative ion $\mathrm{m} / \mathrm{z} 146$ ) is not water soluble, and a reference standard of starch, when analyzed under these conditions, did not respond to electrospray ionization.

\subsection{Extraction Comparison}

Although samples were analyzed by both positive and negative modes, positive ionization produced complex spectra typical of natural DOC (Leenheer et al. 2001; Rostad and Leenheer 2002a, b, 2004), which was not applicable for specific analysis (data not shown), and therefore only negative ionization spectra will be shown.

Analysis by ESI/MS of the samples from the WAX extraction, the most specific method employed, produced an intense response from the Fletcher Out 1 sample (Fig. 3a) but relatively weak response from the Fletcher Out 2 (Fig. 3b) and Fletcher Pond (Fig. 3c). No ions indicative of isopropyl xanthate $(\mathrm{m} / \mathrm{z} 135$; or ethyl xanthate $(\mathrm{m} / \mathrm{z}$ 121)) were observed in these extracts. The WAX extract of Fletcher Mill Out 1 produced strong
Fig. 2 Negative electrospray ionization/mass spectrum of milling reagents. a Sodium isopropyl xanthate, $\left[\left(\mathrm{CH}_{3}\right)_{2}-\right.$ $\mathrm{CH}-\mathrm{O}-\mathrm{C}(=\mathrm{S})-\mathrm{S}]^{-}$; b sodium ethyl xanthate, $\left[\mathrm{CH}_{3}-\mathrm{CH}_{2}-\right.$ $\mathrm{O}-\mathrm{C}(=\mathrm{S})-\mathrm{S}]^{-}$ (a) *MSD1 SPC, time=2.253 of NATCPD7/N1603A.D API-ES, Neg, Scan, Frag: 50, "MS SCAN NEG"

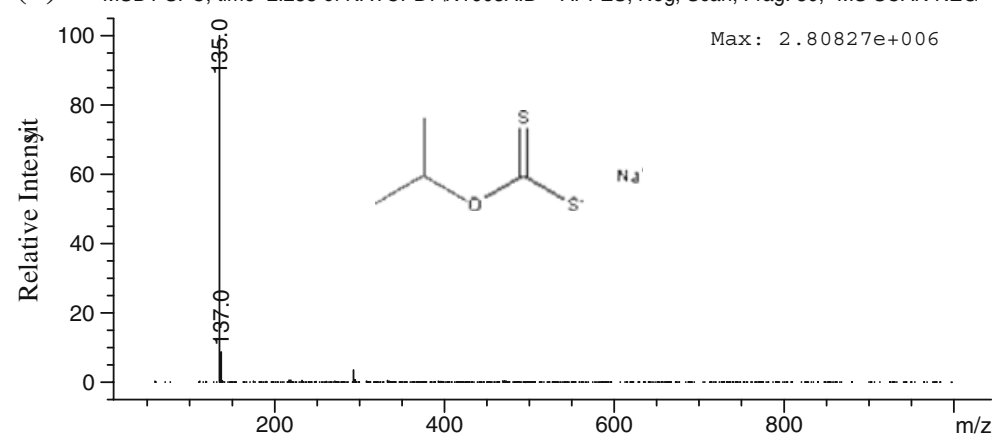

(b) *MSD1 SPC, time=7.304 of NATCPD7IN1603A.D API-ES, Neg, Scan, Frag: 50, "MS SCAN NEG"

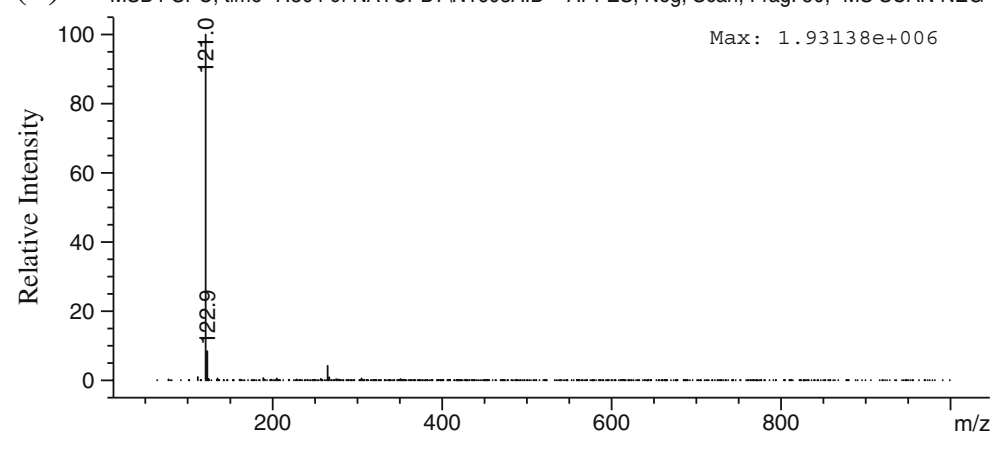


Fig. 3 Electrospray ionization mass spectra of sample extracts from solid-phase extraction using weak anion exchange (WAX). a WAX extract of Fletcher Mill Out 1, b WAX extract of Fletcher Out 2 (weak), c WAX extract of Fletcher Pond (weak) (a) "MSD1 SPC, time=34.715 of MISSOURIIN1668B.D API-ES, Neg, Scan, Frag: 50, "MS SCAN NEG"

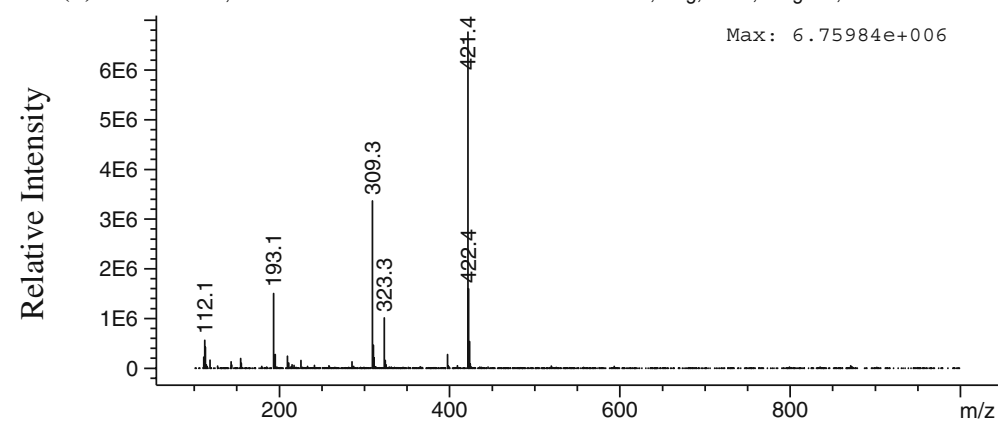

(b) *MSD1 SPC, time=40.776 of MISSOURIIN1668B.D API-ES, Neg, Scan, Frag: 50, "MS SCAN NEG"

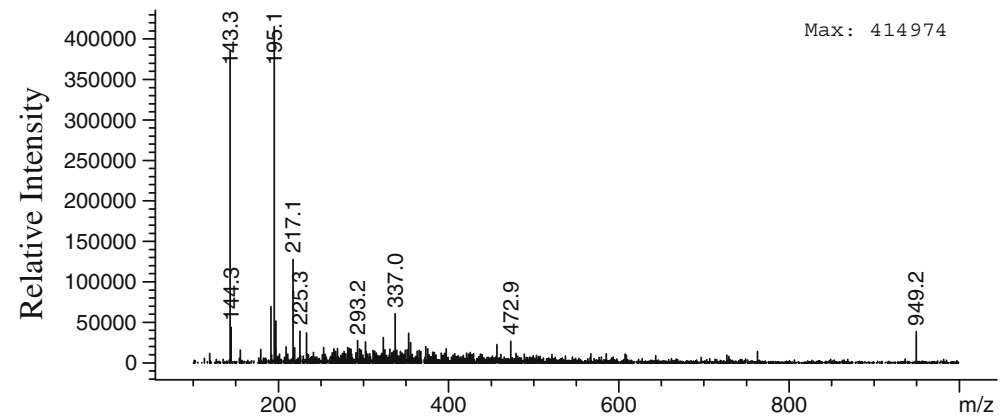

(c) "MSD1 SPC, time=48.928 of MISSOURIIN1668B.D API-ES, Neg, Scan, Frag: 50, "MS SCAN NEG"

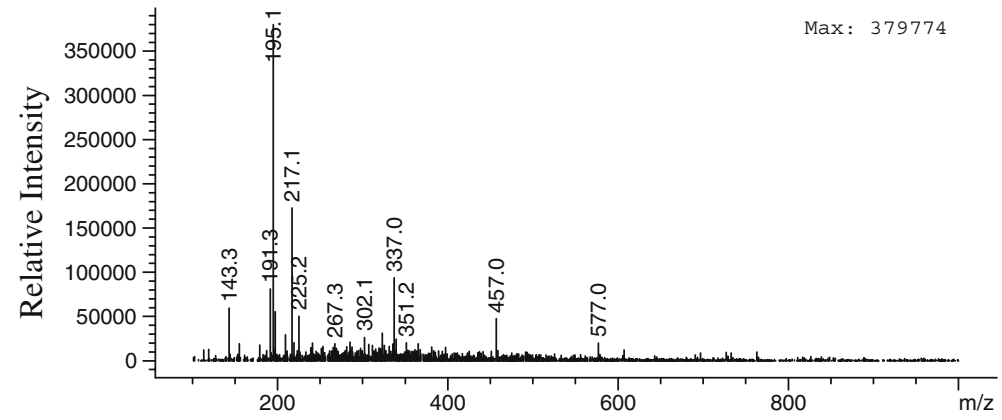

molecular anions at $m / z 421,309$, and 193. The Fletcher Out 2 produced ions at $\mathrm{m} / \mathrm{z} 143$ and 195. The Fletcher Pond extract produced a dominant ion at $m / z$ 195. Identification of the ions is discussed below.

The Oasis HLB extraction isolates a much broader spectrum of organic compounds. All three sample sites produced an intense response by ESI/MS. The Fletcher Mill Out 1 produced strong molecular anions at $m / z$ 421, 247, and 215 (Fig. 4a). The Fletcher Out 2 (Fig. 4b) and Fletcher Pond (Fig. 4c) extracts produced dominant ions at $m / z 215$ and 247. Except for $m / z 421$, the ions isolated by HLB were different than those isolated by WAX.

The sequential XAD extraction produced two extracts per sample. The XAD-8 extract isolates more hydrophobic acidic compounds, whereas the XAD-4 extract isolates relatively less hydrophobic (i.e., transphilic), acidic compounds (Leenheer et al. 2000). Of the XAD-8 extracts, the Fletcher Mill Out 1 produced the strongest response, whereas the Fletcher Out 2 and Fletcher Pond produced relatively weak response. The Fletcher Mill Out 1 spectrum had strong ions at $m / z 421,309,247$, and 
Fig. 4 Electrospray ionization mass spectra of sample extracts from solid-phase extraction using HLB. a HLB extract of Fletcher Mill Out 1, b HLB extract of Fletcher Mill Out 2, c HLB extract of Fletcher Pond (a) ${ }^{*}$ MSD1 SPC, time=6.322 of MISSOURIIN1668B.D API-ES, Neg, Scan, Frag: 50, "MS SCAN NEG"

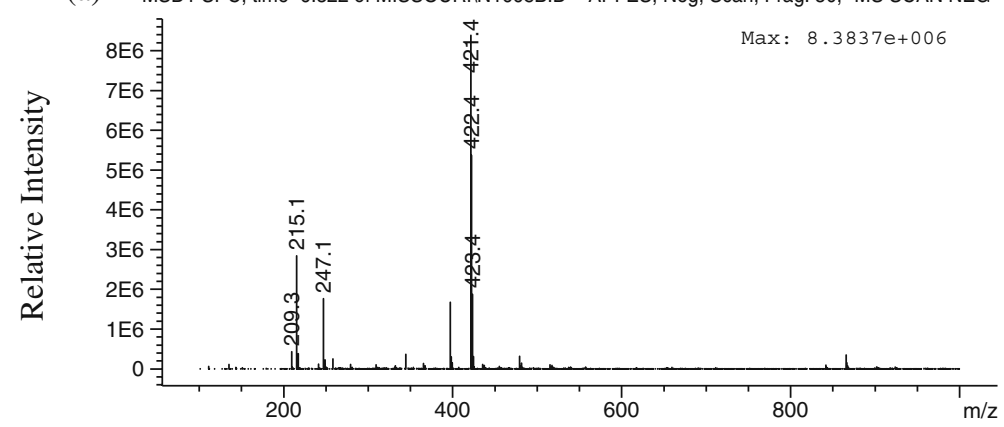

(b) "MSD1 SPC, time=13.429 of MISSOURIN1668B.D API-ES, Neg, Scan, Frag: 50, "MS SCAN NEG"

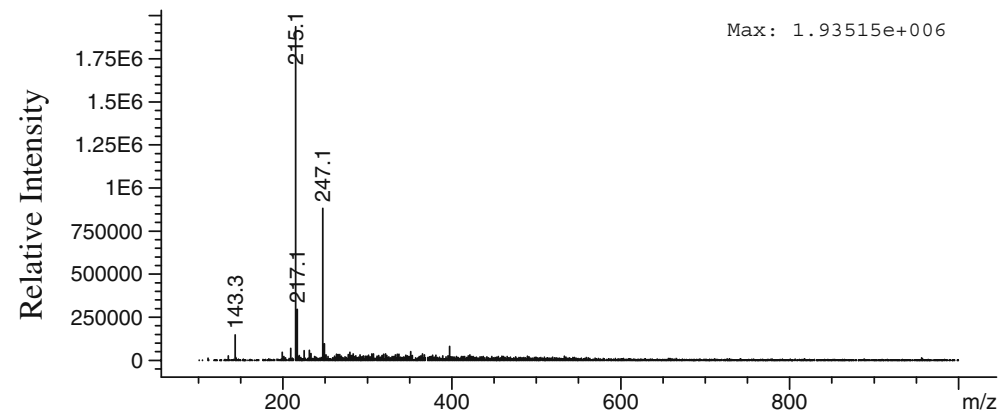

(c) ${ }^{*} M S D 1$ SPC, time=20.518 of MISSOURIIN1668B.D API-ES, Neg, Scan, Frag: 50, "MS SCAN NEG"

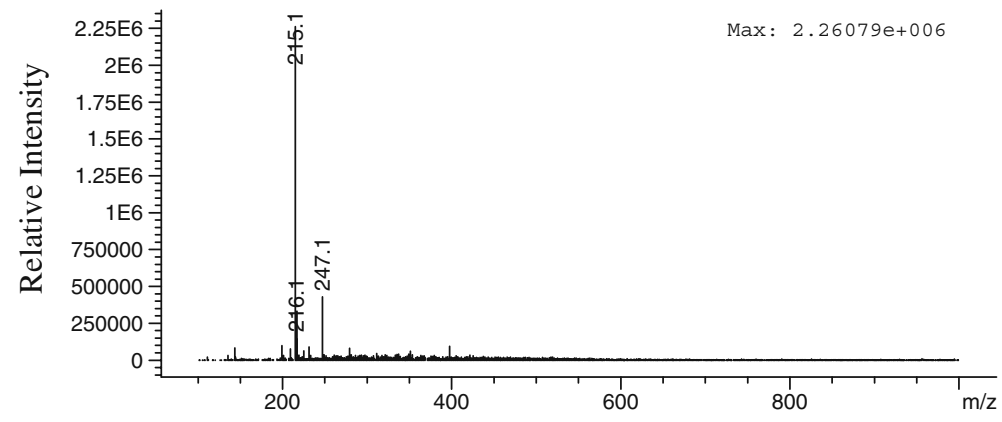

a small 215 (Fig. 5a). The relative intensities of the $\mathrm{m} / \mathrm{z} 421$ and 309 were similar to the response in the WAX extract (Fig. 3a). The Fletcher Out 2 (Fig. 5b) and Fletcher Pond (Fig. 5c) extracts produced weak ions at $m / z 215$ and 247, in similar relative intensities as seen in their HLB extracts (Fig. 4b, c).

The XAD-4 extracts had relative responses that were comparable to the XAD-8 extracts, i.e., strong response from Fletcher Mill Out 1 and weak response from the Fletcher Out 2 and Fletcher Pond. The XAD-4 spectrum of Fletcher Out 1 (Fig. 5d) produced intense ions at $m / z 199,309$, and
421. Extracts of Fletcher Out 2 (Fig. 5e) and Fletcher Pond (Fig. 5f) were dominated by $m / z 199$ and 215, although with different relative intensities. The $\mathrm{m} / \mathrm{z}$ 199 was not observed in extracts by WAX, HLB, or XAD-8. The XAD-8 and XAD-4 extracts do not appear to provide a clear separation because the $\mathrm{m} / \mathrm{z}$ 421 and 309 appear in both extracts, in different relative amounts.

The relative intensities of the dominant ions in each sample spectrum are listed for each type of extraction in Table 2 for comparison, which clearly shows that the compounds isolated vary considerably with the type of SPE used. 
Fig. 5 Electrospray ionization mass spectra of sample extracts from sequential

XAD-8 XAD-4 resin column extraction. a XAD-8 extract of Fletcher Mill Out 1, b XAD-8 extract of Fletcher Mill Out 2, c XAD-8 extract of Fletcher Pond, d XAD-4 extract of Fletcher Mill Out-1, e XAD-4 extract of Fletcher Mill Out 2, f XAD-4 extract of Fletcher Pond (a) "MSD1 SPC, time=77.164 of MISSOURINN1667F.D API-ES, Neg, Scan, Frag: 50, "MS SCAN NEG"

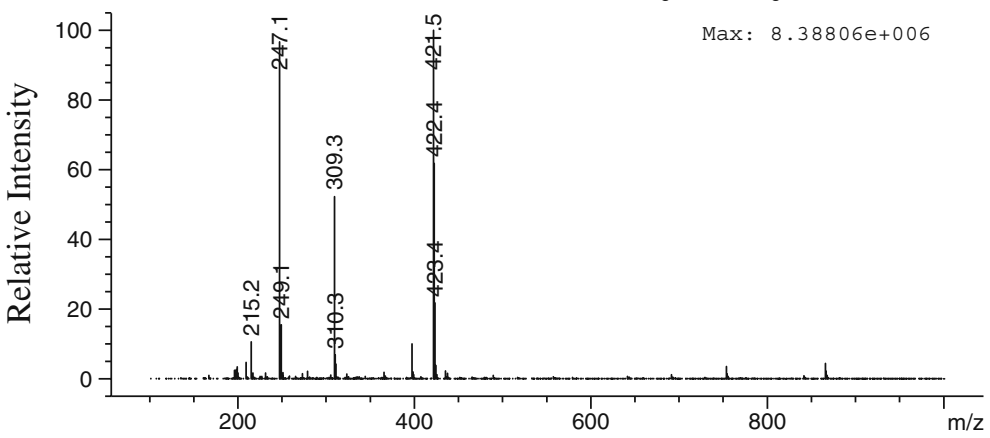

(b) *MSD1 SPC, time=69.082 of MISSOURINN1667F.D API-ES, Neg, Scan, Frag: 50, "MS SCAN NEG"

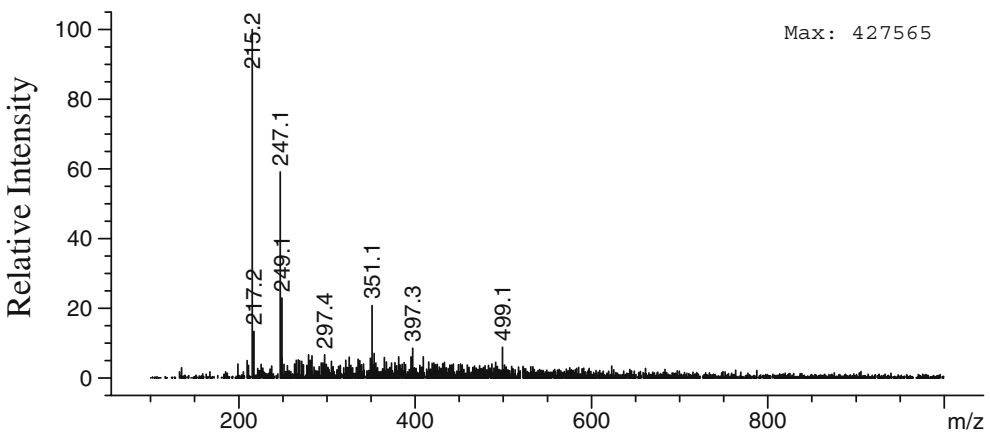

(c) *MSD1 SPC, time=59.973 of MISSOURIIN1667F.D API-ES, Neg, Scan, Frag: 50, "MS SCAN NEG"

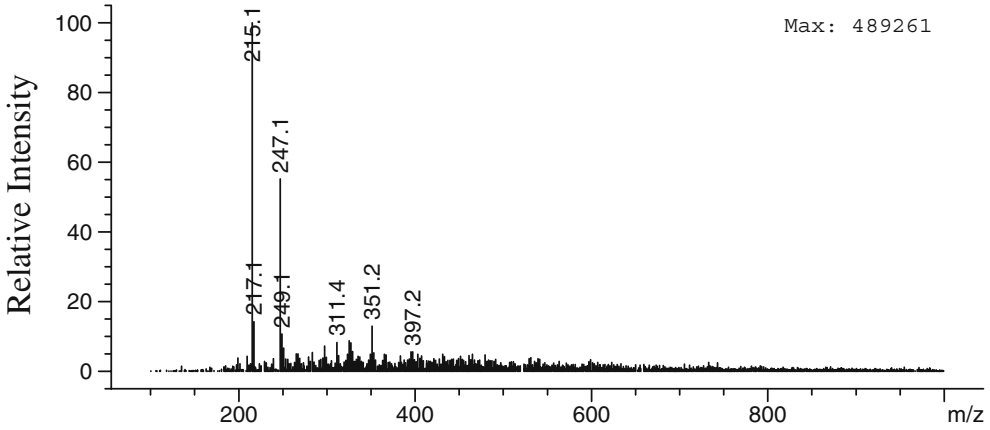

(d) "MSD1 SPC, time=38.687 of MISSOURIN1667F.D API-ES, Neg, Scan, Frag: 50, "MS SCAN NEG"

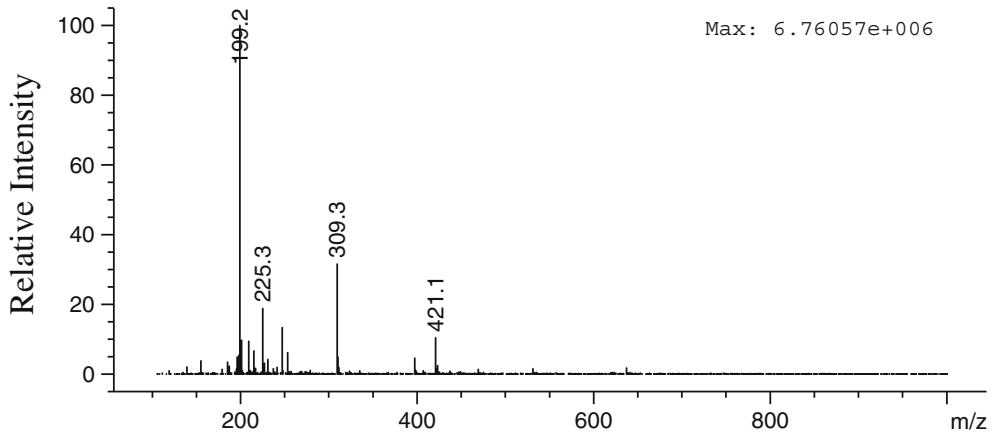


Fig. 5 (continued)

(e) *MSD1 SPC, time=27.575 of MISSOURIN1667F.D API-ES, Neg, Scan, Frag: 50, "MS SCAN NEG"

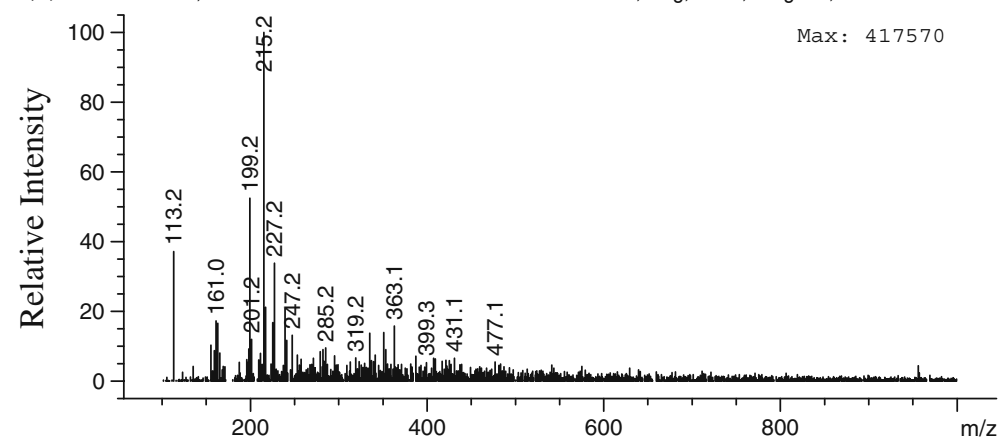

(f) *MSD1 SPC, time=18.448 of MISSOURIN1667F.D API-ES, Neg, Scan, Frag: 50, "MS SCAN NEG"

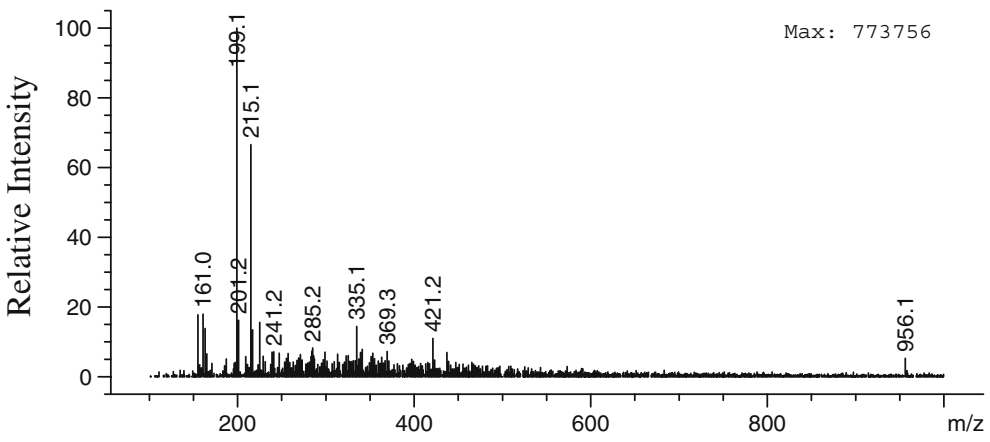

Table 2 Relative intensities of ions from samples from 2006 using various extraction techniques

\begin{tabular}{|c|c|c|c|c|c|c|c|c|}
\hline & \multicolumn{8}{|l|}{$\mathrm{m} / \mathrm{z}$} \\
\hline & 143 & 193 & 195 & 199 & 215 & 247 & 309 & 421 \\
\hline \multicolumn{9}{|c|}{ Fletcher Out 1} \\
\hline WAX & & 25 & & & & & 50 & 100 \\
\hline HLB & & & & & 30 & 20 & & 100 \\
\hline XAD-8 & & & & & 10 & 95 & 50 & 100 \\
\hline XAD-4 & & & & 100 & & & 30 & 10 \\
\hline \multicolumn{9}{|c|}{ Fletcher Out 2} \\
\hline WAX & 90 & & 100 & & & & & \\
\hline HLB & & & & & 100 & 50 & & \\
\hline XAD-8 & & & & & 100 & 60 & & \\
\hline XAD-4 & & & & 50 & 100 & 10 & & \\
\hline \multicolumn{9}{|c|}{ Fletcher Pond } \\
\hline WAX & 20 & & 100 & & & & & \\
\hline HLB & & & & & 100 & 20 & & \\
\hline XAD-8 & & & & & 100 & 60 & & \\
\hline XAD-4 & & & & 100 & 70 & & & \\
\hline
\end{tabular}

\subsection{Compound Identification}

Identification of the ions began with examination of the reagents used at the site. In spite of heavy usage in the mill process, no isopropyl xanthate reagent was found by any of the extraction methods.

The $m / z 421$ was tentatively identified and verified with an authentic reference standard as dioctyl sulfosuccinate (see Fig. 6), a reagent used in the mill process as a filtering aid. This reagent was only found at Fletcher Out 1, not at Fletcher Out 2 or downstream at the Fletcher Pond, by all three extraction techniques. The concentration of dioctyl sulfosuccinate, based on response from the reference standard, at the Fletcher Mill Out 1 site was $350 \mu \mathrm{g} / \mathrm{l}$ based on the HLB extract and $100 \mu \mathrm{g} / \mathrm{l}$ based on the WAX extract.

The $m / z 309$ ion was probably octyl sulfosuccinate (Fig. 6), a degradation product resulting from loss of the alkyl side chain from dioctyl sulfosuccinate (Hales 1993). A reference standard for octyl sulfosuccinate was not available. Octyl sulfosuccinate was detected in Fletcher Mill Out 1 by WAX and XAD extraction, but not by HLB. Whether the octyl sulfosuccinate was present in the technical reagent or was generated as a 


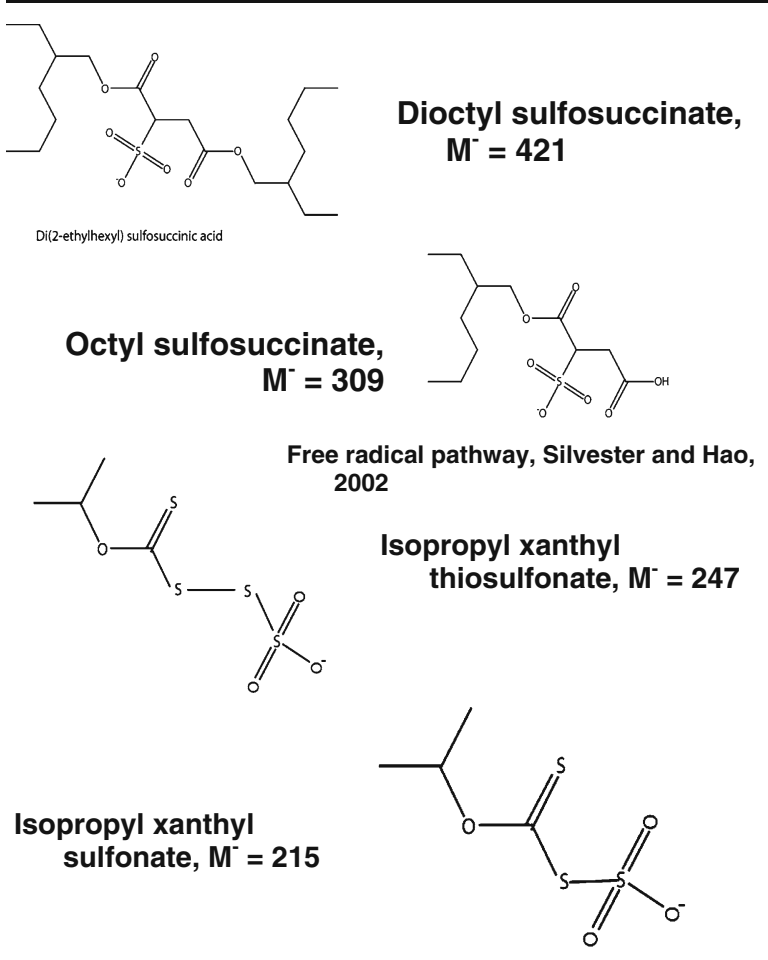

Fig. 6 Proposed structures of observed ions

degradation product is unknown. It was not present in the high-purity reference standard of dioctyl sulfosuccinate analyzed. This demonstrates the importance of using technical-grade reagents (as was done for the xanthates) in environmental studies to include the inert and nonactive ingredients that may be present.

The proposed degradation pathway for dialkyl sulfosuccinate by Hales (1993) described the initial hydrolysis of the ester linkage that is most distant from the sulfonate group, eventually progressing to sulfosuccinic acid (molecular weight, 198). Although sulfosuccinic acid should produce a negative ion at $\mathrm{m} / \mathrm{z} 197$ under negative electrospray ionization, this ion was not observed in any of these extracts. Instead, ions at $m / z 195$ and 193 were observed, but formation of double bonds or small rings to produce a lower molecular weight, more stable ion seems unlikely. If the sulfosuccinic acid had complexed with coincident metal ions, it may not have been extracted or ionized with the techniques shown here.

The $m / z 247$ and 215 ions were likely xanthate concomitant contaminants or degradation products, isopropyl xanthyl thiosulfonate at $\mathrm{M}^{-} \mathrm{m} / \mathrm{z} 247$, and isopropyl xanthyl sulfonate at $\mathrm{M}^{-} m / z 215$ (Fig. 6), via free-radical reaction pathway (Silvester and Hao
2002). Trace amounts of these xanthate degradation products were found in most samples by HLB and XAD extraction. Notably, and although the WAX SPE was selected and tailored for isolation of the isopropyl xanthate, WAX did not isolate the xanthate degradation products. These degradation products have not been reported downstream from milling areas before, and reference standards for these compounds were not available.

The $m / z 199$ ion, seen only in the XAD-4 extracts, may have been from the loss of oxygen from the $\mathrm{m} / \mathrm{z}$ 215 component, since they appear together at all three sites, or from ethyl propyl dithiophosphate or propyl benzene sulfonate, although these possible reagents are not listed as used at this site, and therefore further work is needed to identify it. Although the $\mathrm{m} / \mathrm{z} 199$ ion is very intense from Mill Out 1, it decreases in intensity in Mill Out 2 and in the Pond.

The xanthate degradation products described by Sun and Forsling (1997) were not found in these samples by any of the three extractions. From the isopropyl xanthate $\mathrm{ROCSO}^{-}$, possible xanthate degradation products would include isopropyl monothiocarbanate $\mathrm{ROCSO}^{-}$at $\mathrm{m} / \mathrm{z} 119$, isopropyl dixanthogen $\left[\left(\mathrm{ROCS}_{2}\right)_{2}-\mathrm{H}\right]^{-}$at $m / z 269$, isopropyl xanthic acid ROCS $\left._{2} \mathrm{H}-\mathrm{H}\right]^{-}$at $m / z 135$, and isopropyl perxanthate $\mathrm{ROCS}_{2} \mathrm{O}^{-}$at $m / z$ 151. Xanthate degradation is $\mathrm{pH}$ dependent, and therefore $\mathrm{pH}$ is likely carefully controlled during the mill process.

A product ion scan using tandem mass spectrometry performed on the most intense ions $(m / z 421,309,247$, 215) produced dominant product ions at $\mathrm{m} / \mathrm{z} 81$, indicative of the sulfonate moiety $\left(\mathrm{HSO}_{3}{ }^{-}\right)$, which was expected based on the structures in Fig. 6. This fragment ion dominated the MS/MS spectra; no other fragment ions were produced.

Although a list of what was reportedly used at the sites was available, other milling reagents may also have been used. Spectra were screened for ions indicative of a wide range of common milling reagents and their degradation products. Nevertheless, negative ions indicative of the following milling reagents were not detected: alkylated xanthates (121, 135 , etc.), dialkylated dithiophosphates $(185,213$, etc.), mixed dialkylated dithiophosphates (199, 227, etc.), alkylated dithiocarbamates (120, 134, etc.), alkylated dithionocarbamates (132, 146, etc.), alkylated pyridine thiones $(126,140$, etc.), alkylated octyl phenols 
(205, 219, etc.), alkylated nonyl phenols (219, 233, etc.), and alkylated benzene sulfonates $(185,199$, etc.).

\section{Summary and Conclusions}

Dioctyl sulfosuccinate is an all-purpose surfactant, wetting agent, and solubilizer used in the drug, cosmetic, and food industries and is "Generally Recognized as Safe" by the US Food and Drug Administration (2007) but can cause contact dermatitis (Lee and Lee 1998). The relatively high concentrations of DOC were not attributable to the compounds isolated and identified here. It is possible that the mixed alcohol used as a frothing agent and starch used as the lead depressant contributed to a large portion of the DOC observed. The alcohol would not have been isolated or ionized, and a reference standard of starch did not ionize. Therefore, whether these compounds contribute to the high DOC is unknown. Whether the alcohols, or starch, or other degradation products from the process are discharged from the mill process is unknown. Terpenes and carbohydrates would contribute colorless DOC and, if isolated, would not ionize with electrospray. In order to address this, other techniques to isolate and identify these compounds would be required.

Overall, and in spite of the large amounts of organic compounds used for the extraction of lead, zinc, and copper at the facilities investigated, few milling reagents or their degradation products were detected in process waters or the tailings pond. Dioctyl sulfosuccinate was detected in Fletcher Mill Out 1 by HLB, WAX, and XAD extraction but was not detected further downstream in Fletcher Mill Out 2 or in the tailings pond. Octyl sulfosuccinate was detected in Fletcher Mill Out 1 by WAX and XAD extraction, but not by HLB. Small amounts of isopropyl xanthyl thiosulfonate $(\mathrm{m} / \mathrm{z} 247)$ and isopropyl xanthyl sulfonate $(m / z 215)$ were detected in most samples by HLB and XAD extraction. All of these compounds are both organic and strongly anionic.

Based on this initial exploratory investigation, compounds found in the pond, at $m / z 199,215$, and 247 , are the most likely to persist or be transported downstream. These compounds are likely from the xanthate reagents used in the milling process. Little is known about their fate in the environment.

Although WAX extraction was specifically tailored to isolate isopropyl xanthate and ethyl xanthate, these compounds were not detected. WAX extraction also failed to isolate xanthate degradation products. However, SPE was effective for isolation of these very polar compounds, and the different SPE sorbents isolated different compounds. ESI/MS was successful for analysis, with identification of dioctyl sulfosuccinate, octyl sulfosuccinate, isopropyl xanthyl thiosulfonate, and isopropyl xanthyl sulfonate verified by tandem mass spectrometry. This new application of ESI/MS to mining/milling water samples provided a different approach for characterizing polar organic compounds in these samples.

Acknowledgments We acknowledge the staff from the USGS Missouri Water Science Center who collected water samples and David Alvarez, USGS, Columbia, Missouri, who prepared the POCIS and SPMD units for deployment and converted the POCIS and SPMD units to extracts. Use of trade names in this report is for identification purposes only and does not constitute endorsement by the US Geological Survey. This study was part of a congressionally funded USGS investigation of the effects of mining in the Mark Twain National Forest of Missouri, USA.

\section{References}

Allert, A. L., Fairchild, J. F., DiStefano, R. J., Schmitt, C. J., Brumbaugh, W. G., \& Besser, J. M. (2009). Ecological effects of lead mining on Ozark streams: in-situ toxicity to woodland crayfish (Orconectes hylas). Ecotoxicology and Environmental Safety, 72(4), 1207-1219.

Allert, A. L., Fairchild, J. F., Schmitt, C. J., Besser, J. M., Brumbaugh, W. G., \& Olson, S. J. (2009). Effects of miningderived metals on riffle-dwelling benthic fishes in Southeast Missouri, USA. Ecotoxicology and Environmental Safety, 72(6), 1642-1651.

Besser, J. M., Brumbaugh, W. G., Allert, A. L., Poulton, B. C., Schmitt, C. J., \& Ingersoll, C. G. (2009). Ecological impacts of lead mining on Ozark streams: toxicity of sediment and pore water. Ecotoxicology and Environmental Safety, 72(2), 516-526.

Besser, J. M., Brumbaugh, W. G., May, T. W., \& Schmitt, C. J. (2007). Biomonitoring of lead, zinc, and cadmium in streams draining lead-mining and non-mining areas, southeast Missouri. Environmental Monitoring and Assessment, 129, 227-241.

Brumbaugh, W. G., May, T. W., Besser, J. M., Allert, A. L., \& Schmitt, C. J. (2007). Assessment of elemental concentrations in streams of the New Lead Belt in southeastern Missouri, 2002-05. US Geological Survey Scientific Investigations Report 2007-5057. Washington, DC: US Geological Survey. $57 \mathrm{pp}$.

Brumbaugh, W. G., Schmitt, C. J., \& May, T. W. (2005). Concentrations of cadmium, lead, and zinc in fish from mining-influenced waters of Northeastern OklahomaSampling of blood, carcass, and liver for aquatic bio- 
monitoring. Archives of Environmental Contamination and Toxicology, 49, 76-88.

Cole, R. B. (1997). Electrospray ionization mass spectrometry -Fundamentals, instrumentation, and applications. New York: Wiley-Interscience.

Doe Run Company (2003). Primary mining and smelting division, 2002 annual report to our community, Missouri. http://www.doerun.com/uploadfile/2002 Primary.pdf. Accessed May 2006.

Goldhaber, M. B., Church, S. E., Doe, B. R., Aleinikoff, J. N., Brannon, J. C., Podosek, F. A., et al. (1995). Lead and sulfur isotope investigations of Paleozoic sedimentary rocks from the southern Midcontinent of the United States-Implications for paleohydrology and ore genesis of the southeastern Missouri lead belts. Economic Geology, 90(7), 1875-1910.

Hales, S. G. (1993). Biodegradation of the anionic surfactant dialkyl sulphosuccinate. Environmental Toxicology and Chemistry, 12, 1821-1828.

Imes, J. L. (2002). Geohydrological and biological investigations associated with a new lead-zinc exploration area near Winona, Missouri, and the Viburnum Trend of southeastern Missouri US Geological Survey Fact Sheet FS 0005-02. Washington, DC: US Geological Survey.

Jennett, J. C., \& Callier, A. J. (1977). Trace organic emissions from lead mining-milling operations. Journal of the Water Pollution Control Federation, 49, 469-488.

Lee, A.-Y., \& Lee, K.-H. (1998). Allergic contact dermatitis from dioctyl sodium sulfosuccinate in a topical corticosteroid. Contact Dermatitis, 38, 355-356.

Leenheer, J. A. (1981). Comprehensive approach to preparative isolation and fractionation of dissolved organic carbon from natural waters and wastewaters. Environmental Science and Technology, 15(5), 578-587.

Leenheer, J. A., Croue, J.-P., Benjamin, M., Korshin, G. V., Hwang, C. J., Bruchet, A., et al. (2000). Comprehensive isolation of natural organic matter for spectral characterization and reactivity testing. In S. Barrett, S. W. Krasner, \& G. L. Amy (Eds.), Natural organic matter and disinfection by-products-Characterization and control in drinking water (American Chemical Society Symposium Series, Vol. 761, pp. 68-83). Washington, DC: American Chemical Society.

Leenheer, J. A., Ferrer, I., Furlong, E. T., \& Rostad, C. E. (2002). Charge characteristics and fragmentation of polycarboxylic acids by electrospray ionization, multiple tandem mass spectrometry (ESI/MS/MS). Preprints of extended abstracts, 223rd National Meeting of American Chemical Society, Orlando, FL, USA, April 7-11, 2002, vol. 42(1), pp 365-369.

Leenheer, J. A., Rostad, C. E., Gates, P. M., Furlong, E. T., \& Ferrer, I. (2001). Molecular resolution and fragmentation of fulvic acid by electrospray ionization/multistage tandem mass spectrometry. Analytical Chemistry, 73(7), 1461-1471.

Okibe, N., \& Johnson, D. B. (2002). Toxicity of flotation reagents to moderately thermophilic bioleaching microorganisms. Biotechnology Letters, 24, 2011-2016.

Pawliszyn, J. (2003). Sample preparation: Quo vadis? Analytical Chemistry, 75, 2543-2558.

Rostad, C. E., \& Leenheer, J. A. (2002a). Molecular weight distributions of fractions of dissolved organic carbon by electrospray ionization/mass spectrometry, new analytical techniques for dissolved organic matter symposium. Preprints of extended abstracts, 223rd National Meeting of American Chemical Society, Orlando, Florida, April $7-$ 11, 2002, vol. 42(1), pp 509-512.

Rostad, C. E., \& Leenheer, J. A. (2002b). Molecular weight distributions of Suwannee River fulvic acid by electrospray ionization/mass spectrometry, new analytical techniques for dissolved organic matter symposium. Preprints of extended abstracts, 223rd National Meeting of American Chemical Society, Orlando, Florida, April 7-11, 2002, vol. 42(1), pp 492-495.

Rostad, C. E., \& Leenheer, J. A. (2004). Factors that affect molecular weight distribution of Suwannee River fulvic acid as determined by electrospray ionization/mass spectrometry. Analytica Chimica Acta, 523(2), 269-278.

Rostad, C. E., \& Leenheer, J. A. (2005). Factors that affect molecular weight distribution of fulvic acids as determined by electrospray ionization/mass spectrometry. Advanced Characterization of Natural Organic Matter Symposium, Division of Geochemistry, American Chemical Society, 230th National Meeting, Washington, DC, August 28September 1 .

Schmitt, C. J., Brumbaugh, W. G., \& May, T. W. (2007a). Accumulation of metals in fish from lead-zinc mining areas of southeastern Missouri, USA. Ecotoxicology and Environmental Safety, 67, 14-30.

Schmitt, C. J., Brumbaugh, W. G., May, T. W., \& Besser, J. M. (2007b). Concentrations of metals in aquatic invertebrates from the Ozark National Scenic Riverways, Missouri. US Geological Survey Open-File Report 2007-1435. Washington, DC: US Geological Survey. 23 pp.

Schmitt, C. J., Caldwell, C. A., Olsen, B., Serdar, D., \& Coffey, M. (2002). Inhibition of erythrocyte $\delta$-aminolevulinic acid dehydratase (ALAD) activity in fish from waters affected by smelters. Environmental Monitoring and Assessment, 77, 99-119.

Schmitt, C. J., Wildhaber, M. L., Hunn, J. B., Nash, T., Tieger, M. N., \& Steadman, B. L. (1993). Biomonitoring of leadcontaminated Missouri streams with an assay for erythrocyte D-aminolevulinic acid dehydratase activity in fish blood. Archives of Environmental Contamination and Toxicology, 25, 464-475.

Silvester, E., \& Hao, F. P. (2002). Environmental fate of flotation collectors in mineral processing operationsEthyl xanthate as an example. Green Processing 2002Proceedings: International Conference on the Sustainable Processing of Minerals, Cairns, Queensland, Australia, pp 259-263.

Suffet, I. H., \& MacCarthy, P. (1989). Aquatic humic substances: Influence on fate, and treatment of pollutants (Advances in Chemistry Series, Vol. 219). Washington, DC: American Chemical Society.

Sun, Z., \& Forsling, W. (1997). The degradation kinetics of ethyl-xanthate as a function of $\mathrm{pH}$ in aqueous solution. Minerals Engineering, 10(4), 389-400.

US Environmental Protection Agency. (1994). Technical resource document, extraction and beneficiation of ores and minerals, Volume 1: Lead-zinc, EPA 530-R-94-011, NTIS PB94-170248 (p. 127). Washington, DC: US Environmental Protection Agency. 
US Food and Drug Administration. (2007). Code of Federal Regulations. Title 21, Volume 3, Revised as of April 1, 2007. 21CFR177.2800, http://www.accessdata.fda.gov/ scripts/cdrh/cfdocs/cfCFR/CFRSearch.cfm?fr=177.2800. Accessed 20 March 2008.

US Geological Survey. (2004a). Columbia Environmental Research Center, semipermeable membrane device (SPMD), description and application. www.cerc.usgs.gov/ pubs/center/pdfDocs/SPMD.pdf. Accessed May 2010.

US Geological Survey. (2004b). Columbia Environmental Research Center, polar organic chemical integrative samplers (POCIS), description and application. www. cerc.usgs.gov/pubs/center/pdfDocs/POCIS.pdf. Accessed May 2010.
Waters Corporation. (2003). Oasis application handbook. Milford: Waters Corporation. 195 pp.

Wixson, B. G. (Ed.). (1977). The Missouri lead study-An interdisciplinary investigation of environmental pollution by lead and other heavy metals from industrial development in the New Lead Belt of southeastern Missouri. Final report to the National Science Foundation (Volume 1), University of Missouri-Rolla, MO.

Wixson, B. G., \& Jennett, J. C. (1975). The new lead belt in the forested Ozarks of Missouri. Environmental Science and Technology, 9, 1128-1133.

Xu, Y., Lay, J., \& Korte, F. (1988). Fate and effects of xanthates in laboratory freshwater systems. Bulletin of Environmental Contamination and Toxicology, 41, 683-689. 